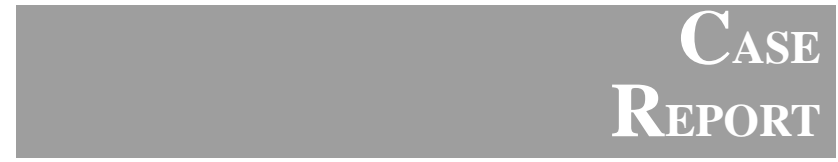

\title{
Esophageal ulcer and alendronate
}

\author{
Division of Gastroenterology, Endoscopy Unit, \\ Universidade Federal de São Paulo/Escola Paulista de Medicina, São Paulo, Brazil
}

\begin{abstract}
Objective: To describe a case of esophageal ulcer associated with the use of alendronate. Case Report: This is the fifth case ever described in the literature according to our bibliographic review. In our patient, the association between the drug and the esophageal lesions was masked by the presence of a hiatal hernia, potentially a cause of the esophageal lesion. The persistence of the lesions despite high doses of anti-reflux therapy called attention to the possibility of the relationship. The esophageal lesion healed soon after suspension of alendronate. Discussion: The authors present a review of the literature and point to the need for diagnostic investigation, to suspend such a drug from patients who experience dyspeptic symptoms while using it.
\end{abstract}

Uniterms: Endoscopy. Alendronate. Esophageal ulcer.

\section{INTRODUCTION}

$\mathrm{T}$ he first description of an association between alendronate and esophageal ulcer was recently reported by Maconi et al. ${ }^{1}$ Few other reports emphasize this relationship. We present a case of a patient using alendronate who developed an esophageal ulcer that, despite anti-secretory therapy, only healed after removal of the drug. The authors present a review of the literature, and to our knowledge, this is the first report in the Brazilian medical literature.

\section{CASE REPORT}

A 53 year old female was diagnosed with osteoporosis during a clinical examination for a dental implant. Treatment was initiated with alendronate $(10 \mathrm{mg} / \mathrm{day})$, calcium carbonate and vitamins A and D supplementation.

\section{Correspondence Address:}

Angelo Paulo Ferrari Jr.

R. Machado Bittencourt, 379 - Apto. 91

São Paulo/SP - Brasil - CEP 04044-001

E-mail: angelo@gastro.epm.br
One week later, the patient began to complain of dysphagia and odynophagia, accompanied by pyrosis. Empirical treatment was initiated for gastro-esophageal reflux with ranitidine (150 $\mathrm{mg}$ every 12 hours), domperidone (10 $\mathrm{mg}$ before meals), and antacid at the patient's discretion. There was no improvement in symptoms, and after one week of treatment an endoscopy was performed that revealed a hiatal hernia and an ulcer in the distal esophagus (Fig. 1), associated with erosions in the mid esophagus (Fig. 2). Esophageal biopsies ruled out the presence of neoplasm, and the lesions were considered to be part of the spectrum of the gastroesophageal reflux disease. The medication was changed to cisapride (10 mg, 4 times/day) and proton pump inhibitor (pantoprazole, $40 \mathrm{mg} / \mathrm{day}$ ). Despite correct use of medication by the patient, and although there was improvement in symptoms, dysphagia and pyrosis persisted.

After one month, endoscopy to re-evaluate the lesion showed the permanence of the ulcer, although inflammatory reaction apparently had improved. It was also noted that extensive erosions of the mid esophagus were still present, with normal mucosa between the two lesions (Fig. 3). Biopsies again were negative for neoplasm. The medication was changed again, increasing the dose of pantoprazole to $40 \mathrm{mg}, 2$ times/day, and was associated with $1 \mathrm{~g}$ of sucralphate, 4 times/day. 
Two weeks later, the patient continued to complain of symptoms. It was decided then to suspend medication for osteoporosis (alendronate) and maintain the antisecretory measures. There was great improvement in the first 48 hours, and a new digestive endoscopy performed after two weeks of improvement in symptoms revealed only the presence of the hiatal hernia, without ulcer or other inflammatory abnormalities (Fig. 4). The antisecretory medication was gradually suspended and the patient is currently off medication and asymptomatic.

\section{DISCUSSION}

Esophageal ulcers can appear as a consequence of gastro-esophageal reflux, mainly in association with hiatal hernias. Although not frequent, the appearance of these ulcers identifies those with severe gastro-esophageal reflux. The presence of hiatal hernia in the case described here was, apparently, a confusing factor in the establishment of a definitive diagnosis. Due to the hernia, the presence of the esophageal ulcer was attributed to gastro-esophageal reflux disease and not to the use of alendronate.

Sodium alendronate is a potent aminobiphosphonate that inhibits bone reabsorption through the inhibition of osteoclastic activity. Contrary to the first and second generation biphosphonates (etidronate, chlodronate), that were associated with pronounced and frequent adverse effects (vomiting, diarrhea, dyspepsia), alendronate is apparently much more tolerable. ${ }^{2}$ In addition, its effect on the prevention of fractures due to osteoporosis has been proven. ${ }^{3}$ Its use for the treatment of osteoporosis during menopause has shown progressive increase in bone mass and decreases in vertebral fracture incidence and height loss over a period of three years. ${ }^{4}$

In 1996, Maconi et al. ${ }^{1}$ were the first to describe the possible link between alendronate and esophageal ulcers. In their report, a 59 year old patient had retrosternal pain, odynophagia and dysphagia, some days after having initiated therapy with alendronate, $5 \mathrm{mg} /$ day. Endoscopy revealed esophageal erosions and she was medicated with omeprazole. After 8 weeks, endoscopy did not reveal any other abnormalities. The authors emphasize the fact that the patient was taking the alendronate pills with little water and while lying in bed, from which one could suppose that the esophageal lesion had been caused by direct contact of the drug with the esophageal mucosa. In our case, this did not seem to be an important factor, since the patient followed the directions concerning the proper way to take the medication.

De Grown et al. ${ }^{4}$ described 3 cases of esophageal lesion associated with the use of alendronate. In all of the

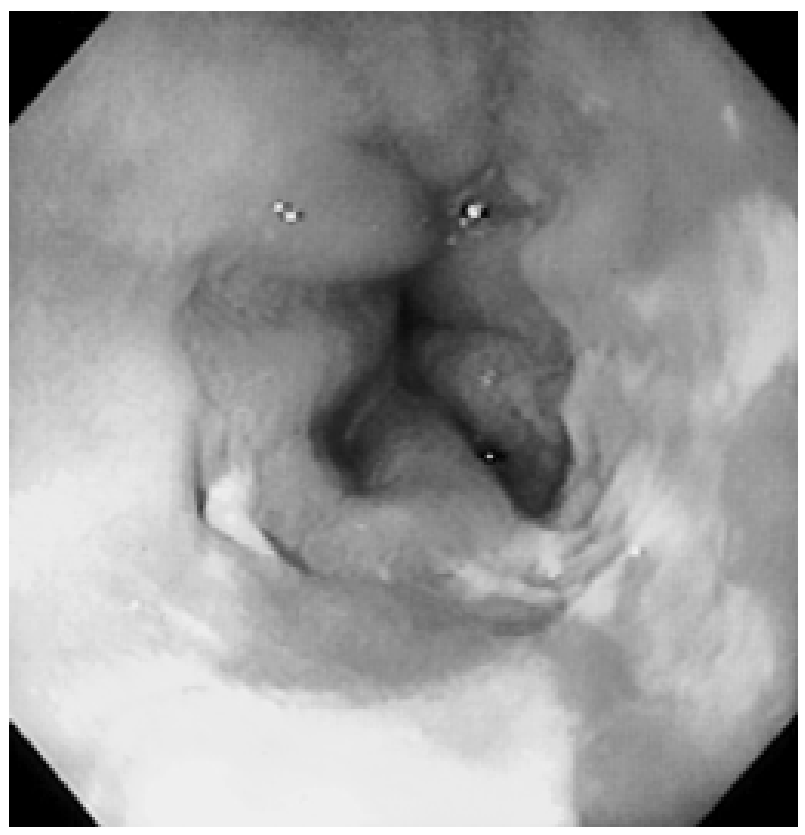

Figure 1 - First endoscopy picture. A small hiatal hernia is seen, with large superficial ulceration.

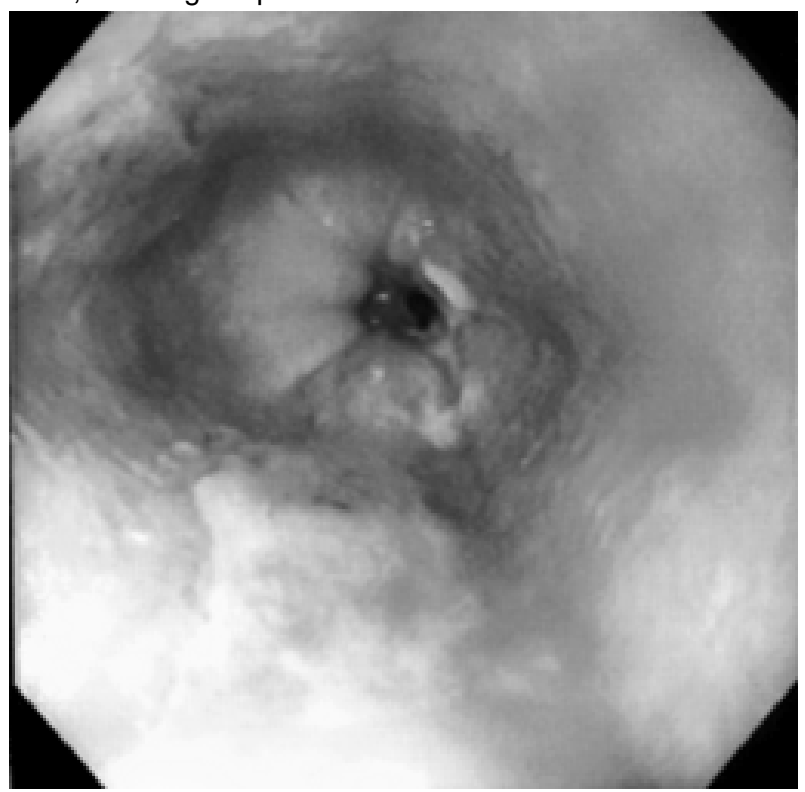

Figure 2 - The endoscope is positioned in the mid esophagus and superficial erosions can be seen.

patients, the lesion was extensive and severe, and the esophageal lesions, as well as the symptoms, only improved after suspension of alendronate, in spite of high doses of anti-secretory drugs. In one of the cases reported, esophageal lesions were severe enough to cause hematemesis and stenosis. In addition to the description of the three cases, the authors present a review of 5000 medicated patients, with 1213 patients reporting side effects. Among such effects, 199 involved the esophagus, and they were considered serious in 52 patients $(26 \%)$. The lesions were distributed equally between the middle 


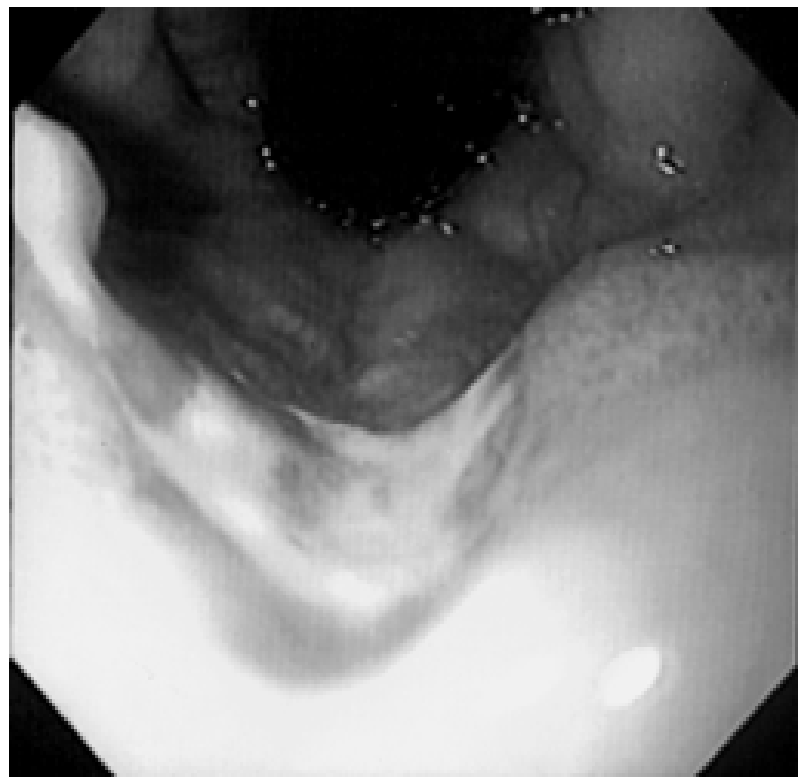

Figure 3 - An esophageal ulcer in the esophago-gastric transition can be seen in this retroflexed (U-turn) view.

and distal esophagus, and in some cases, the entire organ. The symptoms appeared precociously, in the first month after the initiation of the alendronate, and most patients did not have any history of gastrointestinal disease.

The physiopathology of the esophageal lesions caused by alendronate is still unknown. The hypothesis that the drug causes lesions through direct contact with the mucosa seems to be quite reasonable. Some of the patients with lesions refer to the ingestion of the medication with an amount of water less than that recommended, or even in a supine position, making the passage of the capsule through the esophagus difficult. In addition, the presence of hiatal hernia and gastro-esophageal reflux could favor the reflux of the drug even after the pill reaches the stomach. ${ }^{4}$

In any event, while such a mechanism remains unclarified, patients who need to use the medication must be oriented to take the pills with at least 1 glass of water, and not lay down for at least one hour. This could minimize the effects of drug contact with the esophageal mucosa. Furthermore, the appearance of symptoms that suggest

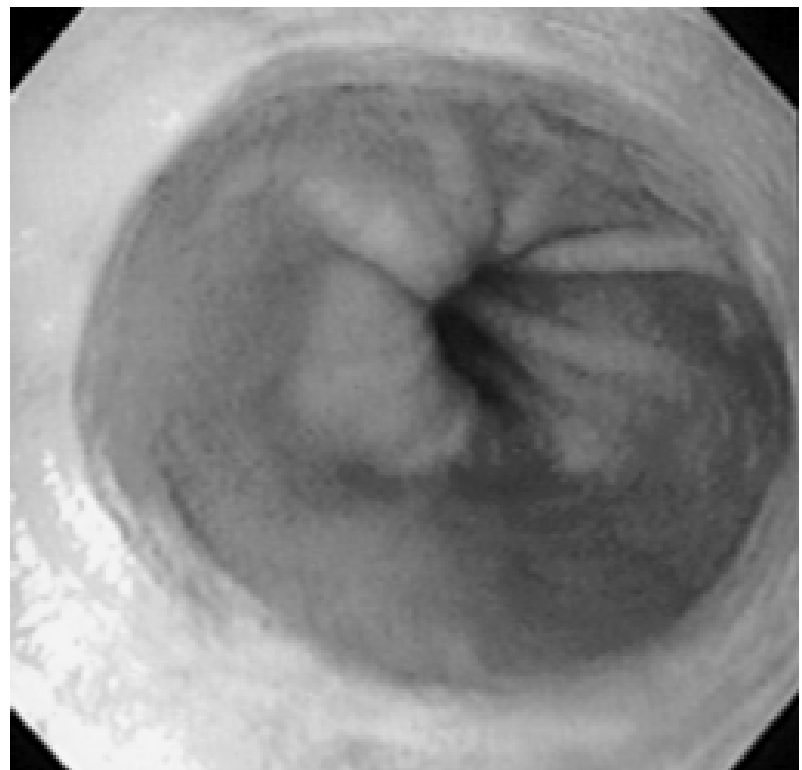

Figure 4 - After the patient had stopped alendronate, upper endoscopy showed a hiatal hernia without any ulceration.

esophageal lesions (dysphagia, odynophagia, pyrosis) must be investigated immediately with upper digestive endoscopy to evaluate the degree of the lesion. The suspension of medication is fundamental to the healing of serious lesions.

\section{REFERENCES}

1. Maconi G, Porro GB. Multiple ulcerative esophagitis caused by alendronate. Am J Gastroenterol 1996; 90(10):1889-90.

2. Harris ST, Gertz BJ, Genant HK, et al. The effect of short term treatment with alendronate on vertebral density and biochemical markers of bone remodelling in early postmenopausal women. J Clin Endocrinol Metab 1993;76:1399-406.

3. Lieberman UA, Weiss SR, Bröll J, et al. Effect of oral alendronate on bone mineral density and the incidence of fractures in menopausal osteoporosis. N Engl J Med 1995;333(22):1437-43.

4. De Groen PC, Lubbe DF, Hirsch LJ, et al. Esophagitis associated with the use of alendronate. N Engl J Med 1996;335:1016-21.

\section{Resumo}

Objetivo: Descrever um caso de úlcera esofágica associada ao uso de alendronato. Relato de caso: Este, segundo nossa pesquisa bibliográfica, é o quinto caso descrito na literatura. Em nossa paciente, a associação entre a droga e a lesão esofágica foi mascarada pela presença de hérnia de hiato, potencialmente causadora de lesão de esôfago. A persistência da lesão apesar de doses elevadas de medicação anti-refluxo gastro-esofágica alertou para a possível associação. A lesão esofágica cicatrizou logo após a retirada do alendronato. Discussão: Os autores fazem uma revisão da literatura e alertam para a necessidade de investigação diagnóstica e retirada da droga, em pacientes em uso de alendronato e que desenvolvem queixas dispépticas. 